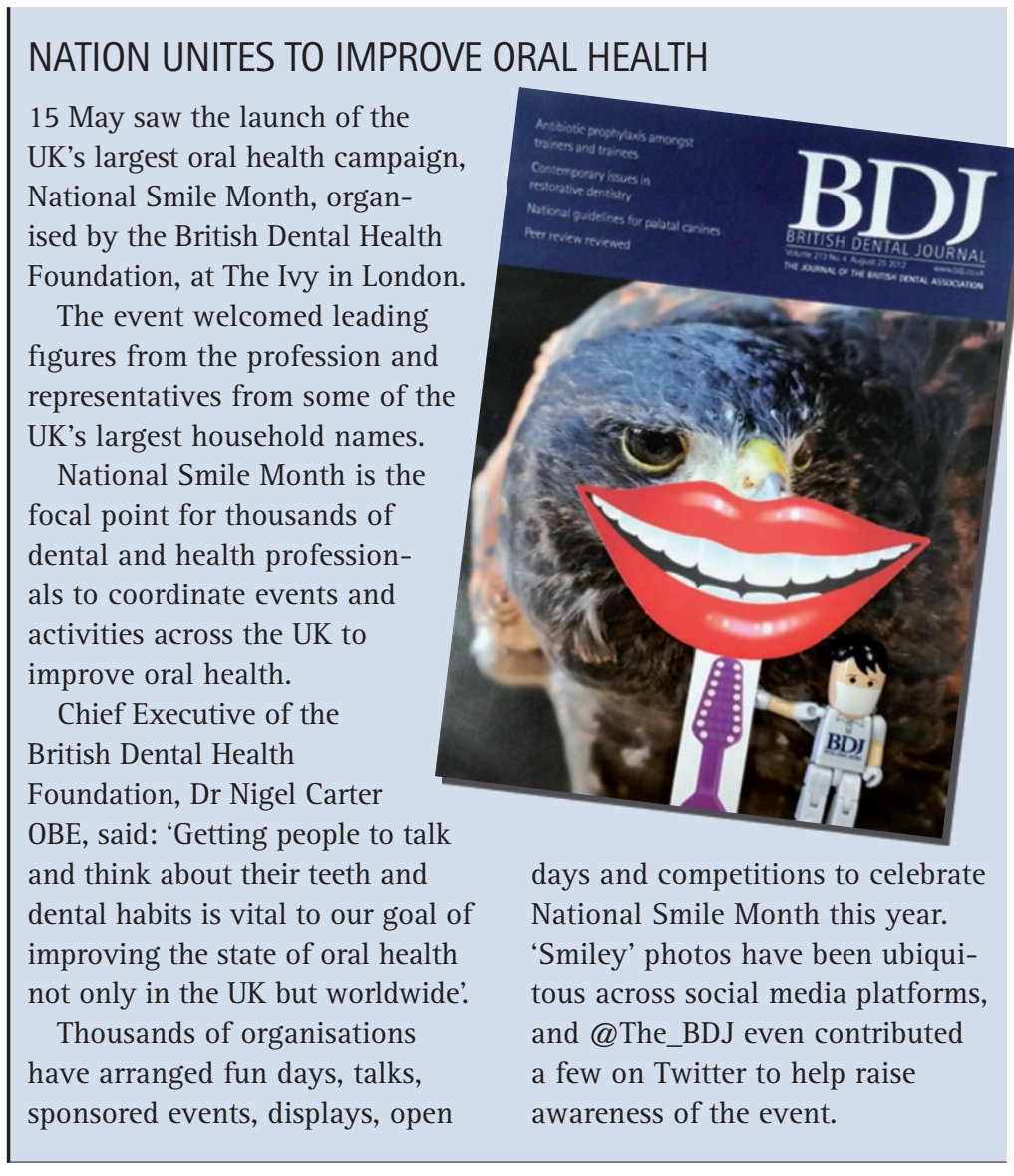

\section{PAIN RELIEF CLINIC CELEBRATES 15 YEARS}

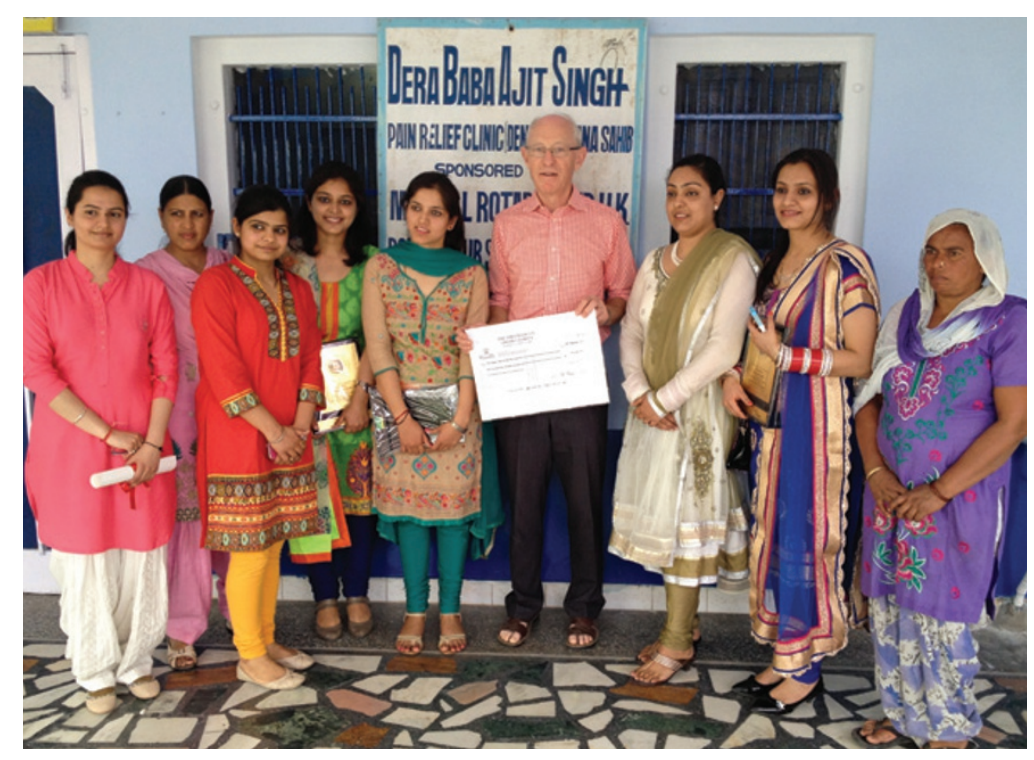

The Pain Relief Dental Clinic at the small village of Hansali in the Punjab, India celebrated its fifteenth anniversary on 8 February 2014 and marked it on 15 March. Hardev Coonar, Emeritus Consultant Oral Surgeon, was instrumental in establishing the clinic as a Rotary Project on his retirement from the Eastman Dental Hospital and Hammersmith Hospital in 1999. The clinic is sponsored by the Rotary Club of
Mill Hill and hosted by the Rotary Club of Sirhind/Punjab. Dr Richard Dunstan from London attended the anniversary celebration in March, and is pictured here with the cur-

In 15 years the four-chair clinic has provided free dental care to 129,000 patients in rural Punjab and volunteers from many parts of the world have travelled to the clinic to offer their services in the spirit of 'service above self'. rent team at Hansali.
MYTH-BUSTING

\section{DONKEY DENTISTRY AND OTHER STORIES}

Maintaining good oral health should be part of everyone's daily routine but sometimes tradition and superstition get in the way. A perfect example of this was discovered in the $B D J$ archives from a century ago:

At the Dorset Field Club's meeting on February 3, Mr Rawlence, of Salisbury, quoted instances of superstitious folk-lore in Dorset. As recently as 1910 a leading auctioneer in the county told him he had been suffering from toothache and on the way to the dentist he met an old farmer client, who, learning where he was going, said: 'Don't go there; I'll tell 'ee how to cure it. You go to a young oak tree and put your arms round it and mark the place where your fingers meet. Then hit a slit in the bark with your knife, put your left hand behind your head and pull out some hair behind your right ear, and put it in the slit of the bark and you'll never have toothache again.' (BDJ 1914; 35.)

However fantastical, it is impossible that such measures could do anything to prevent the recurrence of toothache and yet it is not impossible that the auctioneer in this report attempted this creative solution to rid himself of toothache. Whilst the farmer's suggestion might seem ridiculous in the twenty-first century, many old wives' tales persist today and it must be questioned whether there are scientific explanations behind their efficacy or if they are simply inaccurate and potentially dangerous to the patient.

\section{Chewing on cloves to relieve toothache}

Cloves have traditionally been thought to cure toothache and this old wives' tale has scientific merit. Cloves contain eugenol, a phenylpropene that is commonly used in medicine and dentistry as a local antiseptic and anaesthetic. Chewing on cloves therefore releases this chemical and can serve to numb and clean the affected area.

\section{Overjet as a result of thumb-sucking}

Thumb-sucking is a habit that most parents try to discourage, mainly due to fear that it will result in their child developing maxillary incisors that project forward. Whilst this type of malocclusion can be predetermined by genetics if the lower jaw is smaller than the upper jaw, oral habits such as thumb-sucking can worsen the resultant protrusion by creating outward pressures during growth. However, thumb-sucking is generally not the sole cause of what is colloquially known as 'buck teeth'.

Rubbing whisky on a baby's sore gums during teething Folklore recommends dabbing whisky on to a baby's gums to reduce the pain of teething and this method has been similarly practised by adults suffering from toothache. As a narcotic, alcohol will numb the pain, 